\title{
Desmoplastic Melanoma
}

National Cancer Institute

\section{Source}

National Cancer Institute. Desmoplastic Melanoma. NCI Thesaurus. Code C37257.

A melanoma of the skin characterized by a proliferation of atypical spindled melanocytes

in the dermis, in a background of abundant collagen. It usually presents as an amelanotic raised nodular lesion. 